Excess Ther nodynamic Functi ons of Sol uti ons of Al cohol s wi th Sat ur at ed Hydrocarbons: Appl i cat i on of the UN QUAC Equat i on to the Associ at ed Sol ut i on Theory

\begin{tabular}{|l|l|}
\hline 著者 & Nagat a I samu, Kawamur a Yuj i \\
\hline 著者別表示 & 長田 勇 \\
\hline $\begin{array}{l}\text { j our nal or } \\
\text { publ i cat i on ti t l e }\end{array}$ & Zei t schr i ft fur Physi kal i sche Chem e \\
\hline vol une & 107 \\
\hline number & 2 \\
\hline page r ange & $141-158$ \\
\hline year & 1977 \\
\hline URL & ht t p: //doi . or g/10. 24517/00049730 \\
\hline
\end{tabular}


Zeitschrift für Physikalische Chemie Neue Folge, Bd. 107, S. 141-158 (1977) (C) by Akademische Verlagsgesellschaft, Wiesbaden 1977

\title{
Excess Thermodynamic Functions of Solutions of Alcohols with Saturated Hydrocarbons: Application of the UNIQUAC Equation to the Associated Solution Theory
}

\author{
By \\ Is AMU NagATa and YuJi Kawamura \\ Department of Chemical Engineering, Kanazawa University, \\ Kodatsuno, Kanazawa, 920, Japan
}

(Received December 6, 1977)

Association models / UNIQUAC equation / Excess Gibbs free energy / Excess enthalpy / Alcohol-inert component systems

Two continuous association models (the KRETSCHMER-Wrebe and the MECKEKEMPTER types) are combined with the UNIQUAC equation of ABraMs and Pratdsnta to derive expressions for the excess Gibbs free energy and excess enthalpy of alcohol-inert component systems. In data reduction, the structural parameters of pure components are obtained by the method proposed by VERA et al. The present theory is successfully applied to the correlation of the excess thermodynamic functions of cycloalkanol-cycloalkane systems. Ternary results predicted from binary parameters are shown to be in good agreement with experimental excess properties for the ethanol-cyclohexane-n-heptane system at $20^{\circ} \mathrm{C}$.

Die von Kretschmer-Wiebe und Mecke-Kempter entwickelten Modellvorstellungen zur theoretischen Beschreibung der Assoziation von Alkoholen in inerten Lösungsmitteln werden mit der UNIQUAC-Beziehung von ABraMS und Prausnitz kombiniert. Die Struktur-Parameter der reinen Komponenten werden nach der Methode von Vera et al. bestimmt. Die Ergebnisse der Berechnungen von Excess-Thermodynamischen Funktionen auch von binären Mischlösungen cyclischer Alkohole in Cyclo-Alkanen sind in den Tabellen 3 und 4 zusammengefaßt. Ergebnisse von Berechnungen auch am ternären System Äthanol-Cyclohexan-n-Heptan mit Hilfe von Parametern aus binären Systemen sind in guter Ưbereinstimmung mit experimentellen Daten, (Tabelle 5). 


\section{Introduction}

Many investigators have considered the hydrogen bonding of alcohol molecules, which leads to the formation of linear polymeric alcohol complexes, as a main cause of the large deviation from an ideal solution that alcohol-saturated hydrocarbon solutions show. These approaches are called as chemical solution theories whose characteristic is to use several chemical equilibrium constants to fit experimental data. KRETSCHMER and WIEBE [1] formulated the size effect of the alcohol complexes by using the nonathermal Flory-Huggins equation. RENON and Pradsnitz [2] studied the Kretschmer-Wiebe equation to reduce experimental vapor-liquid equilibrium and excess enthalpy data for binary solutions of alcohols and saturated hydrocarbons. WIEHE and BAGLEY [3] derived a Mecke-Kempter type equation based on the athermal Flory-Huggins equation by incorporating the ratio of the molar volume of alcohol to that of hydrocarbon as an adjustable parameter. The Wiehe-Bagley equation can not estimate well the excess enthalpy data. Nagata $[4,5]$ showed that the physical term (the Scatchard-Hildebrand equation) of the nonathermal FloryHuggins equation can be replaced by a new two-parameter equation and the resultant equations are more flexible than the previous equation in data reduction. Abrams and Pradsnitz [6] presented the UNIQUAC (universal quasichemical) equation as the generalization of the theory of GUGGENHEIM [7] to mixtures containing molecules of different size and shape by introducing the local composition concept proposed by WILson [8], showing that the UNIQUAC equation may be used to represent the properties of polymer solutions. One of the advantages of the UNIQUAC equation is to represent liquid-liquid equilibria for a variety of mixtures.

We discuss here the application of the UNIQUAC equation to associated solutions, because the derived associated solution theory may be used to correlate ternary liquid-liquid equilibrium data for alcohol-nonassociating component systems having an immiscible region between nonassociating components while the equations proposed by NaGata $[4,5]$ are unable to do so.

\section{Theory}

According to Abrams and Pradsnitz [6], the UNIQUAC equation for a multicomponent system is expressed by

$g^{E}=g^{E}$ (combinatorial) $+g^{E}$ (residual) 


$$
\begin{aligned}
& g^{E} \text { (combinatorial) } / R T=\sum_{i} x_{i} \ln \left(\varphi_{i} / x_{i}\right)+(Z / 2) \sum_{i} q_{i} x_{i} \ln \left(\theta_{i} / \varphi_{i}\right) \\
& g^{E}(\text { residual }) / R T=-\sum_{i} x_{i} q_{i} \ln \left(\sum_{j} \theta_{j} \exp \left\{-\left(u_{j i}-u_{i i}\right) / R T\right\}\right)
\end{aligned}
$$

where the average area fraction $\theta$ and the average segment fraction $\varphi$ are defined by

$$
\begin{aligned}
\theta_{i} & =q_{i} x_{i} / \sum_{j} q_{j} x_{j} \\
\varphi_{i} & =r_{i} x_{i} / \sum_{j} r_{j} x_{j}
\end{aligned}
$$

where $x$ is the mole fraction, $Z$ is the coordination number equal to 10 and $q$ and $r$ are pure component structural parameters. Eq. (3) shows that there are two adjustable parameters per binary.

\section{Excess Gibbs Free Energy}

A refers to the alcohol (component 1) and 2 and 3 stand for inert components. Continuously associated solution models are based on the following fundamental assumptions:

1. The alcohol forms linear hydrogen-bonded polymers by consecutive chemical reactions of the type $A_{1}+A_{i-1}=A_{i}$.

2. The segment number of an alcohol $i$-mer $A_{i}$ is given by that of a monomer multiplied by the degree of polymerization $i$.

3. Both chemical and physical contributions are responsible for deviations from an ideal solution of alcohols and saturated hydrocarbons.

The previous approaches have shown that the chemical contribution term is concerned with the combinatorial term of the Gibbs free energy of mixing, which is obtained from Eq. (2)

$$
\begin{aligned}
& g^{M} \text { (combinatorial) } / R T=\sum_{i}^{\infty} n_{A_{i}} \ln \varphi_{A_{i}}+n_{2} \ln \varphi_{2}+n_{3} \ln \varphi_{3} \\
& \quad+(Z / 2)\left[\sum_{i}^{\infty} q_{A_{i}} n_{A_{i}} \ln \left(\theta_{A_{i}} / \varphi_{A_{t}}\right)+q_{2} n_{2} \ln \left(\theta_{2} / \varphi_{2}\right)+q_{3} n_{3} \ln \left(\theta_{3} / \varphi_{3}\right)\right]
\end{aligned}
$$

where $n$ is the mole number of chemical species. 
The chemical potentials are obtained by differentiating Eq. (6) with respect to the number of moles of each chemical species.

$$
\begin{aligned}
\Delta \bar{g}_{A_{i}}=R T\left[\ln \varphi_{A_{i}}\right. & +(Z / 2) q_{A_{i}} \ln \left(\theta_{A_{i}} / \varphi_{A_{i}}\right)+\sum_{j}^{\infty} \varphi_{A_{i}}\left(l_{A_{i}}-r_{A_{i}} l_{A_{j}} / r_{A_{j}}\right) \\
& \left.+\varphi_{2}\left(l_{A_{i}}-r_{A_{i}} l_{2} / r_{2}\right)+\varphi_{3}\left(l_{A_{i}}-r_{A_{i}} l_{3} / r_{3}\right)\right]
\end{aligned}
$$

where $l$ is called the bulk factor [9] and it is defined by

$$
l=(Z / 2)(r-g)-r+1 \text {. }
$$

Prigogine and Defay [10] showed that the chemical potential of stoichiometric component 1 is equal to that of the monomer of the same component in the associated solution.

$$
\begin{aligned}
\Delta \bar{g}_{A_{1}}=R T\left[\ln \varphi_{A_{1}}\right. & +(Z / 2) q_{A_{1}} \ln \left(\theta_{A_{1}} / \varphi_{A_{1}}\right)+\sum_{j}^{\infty} \varphi_{A_{1}}\left(l_{A_{1}}-r_{A_{1}} l_{A_{j}} / r_{A_{j}}\right) \\
& \left.+\varphi_{2}\left(l_{A_{1}}-r_{A_{1}} l_{2} / r_{2}\right)+\varphi_{3}\left(l_{A_{1}}-r_{A_{1}} l_{3} / r_{3}\right)\right]
\end{aligned}
$$

We take the pure alcohol as a new reference state.

$$
\Delta \bar{g}_{A_{1}}^{\circ}=R T\left[\ln \varphi_{A_{1}}^{\circ}+(Z / 2) q_{A_{1}} \ln \left(\theta_{A_{1}}^{\circ} / \varphi_{A_{1}}^{\circ}\right)+\sum_{j}^{\infty} \varphi_{A_{j}}^{\circ}\left(l_{1}-r_{1} l_{A_{j}} / r_{A_{j}}\right)\right] \text {. }
$$

The chemical potential of alcohol with the new reference state is derived by subtracting Eq. (10) from Eq. (9)

$$
\begin{aligned}
\Delta \bar{g}_{A_{1}}^{E}=\Delta \bar{g}_{A_{1}} & -\Delta \bar{g}_{A_{1}}^{\circ}=R T\left[\ln \left(\varphi_{A_{1}} / \varphi_{A_{1}}^{\circ}\right)+(Z / 2) q_{1} \ln \left(\theta_{A_{1}} \varphi_{A_{1}}^{\circ} / \varphi_{A_{1}} \theta_{A_{1}}^{\circ}\right)\right. \\
& +\sum_{j}^{\infty} \varphi_{A_{j}}\left(l_{1}-r_{1} l_{A_{j}} / r_{A_{j}}\right)+\varphi_{2}\left(l_{1}-r_{1} l_{2} / r_{2}\right)+\varphi_{3}\left(l_{1}-r_{1} l_{3} / r_{3}\right) \\
& \left.-\sum_{j}^{\infty} \varphi_{A_{j}}^{\circ}\left(l_{1}-r_{1} l_{A_{j}} / r_{A_{j}}\right)\right] .
\end{aligned}
$$

The last four terms on the right hand side of Eq. (11 a) are rearranged as shown in Appendix 1. $\theta_{A_{1}} / \varphi_{A_{1}}=\theta_{1} / \varphi_{1}$ and $\theta_{A_{1}}^{\circ} / \varphi_{A_{1}}^{\circ}=1$ from Eq. (23).

Then, we get

$$
\begin{aligned}
\Delta \bar{g}_{A_{1}}^{E} / R T & =\ln \left(\gamma_{1} x_{1}\right)_{\mathrm{chem}}=\ln \left(\varphi_{A_{1}} / \varphi_{A_{1}}^{\circ}\right)+(Z / 2) \ln \left(\theta_{1} / \varphi_{1}\right)+r_{1} / S^{\circ}-r_{1} / S \\
& +r_{1}\left\{\left(1-l_{1}\right) \varphi_{1} / r_{1}+\left(1-l_{2}\right) \varphi_{2} / r_{2}+\left(1-l_{3}\right) \varphi_{3} / r_{3}\right\}+l_{1}-1
\end{aligned}
$$


where $S$ is the total segment number of one mole of the solution and $S^{\circ}$ is the value of $S$ in pure alcohol state.

$$
\begin{aligned}
1 / S & =\sum_{j}^{\infty} \varphi_{A_{j}} / r_{A_{j}}+\varphi_{2} / r_{2}+\varphi_{3} / r_{3} \\
1 / S^{\circ} & =\sum_{j}^{\infty} \varphi_{A_{j}}^{\circ} / r_{A_{j}} .
\end{aligned}
$$

We may obtain the chemical potentials of the components 2 and 3 without changing the reference state (pure components 2 and 3 ).

$$
\begin{aligned}
\Delta \bar{g}_{2} / R T & =\ln \left(\gamma_{2} x_{2}\right)_{\mathrm{chem}}=\ln \varphi_{2}+1-r_{2} / \mathrm{S}+(Z / 2) q_{2} \ln \left(\theta_{2} / \varphi_{2}\right) \\
& +r_{2}\left\{\left(1-l_{1}\right) \varphi_{1} / r_{1}+\left(1-l_{2}\right) \varphi_{2} / r_{2}+\left(1-l_{3}\right) \varphi_{3} / r_{3}\right\}+l_{2}-1 \\
\Delta \bar{g}_{3} / R T & =\ln \left(\gamma_{3} x_{3}\right)_{\mathrm{chem}}=\ln \varphi_{3}+1-r_{3} / S+(Z / 2) q_{3} \ln \left(\theta_{3} / \varphi_{3}\right) \\
& +r_{3}\left\{\left(1-l_{1}\right) \varphi_{1} / r_{1}+\left(1-l_{2}\right) \varphi_{2} / r_{2}+\left(1-l_{3}\right) \varphi_{3} / r_{3}\right\}+l_{3}-1 .
\end{aligned}
$$

Finally, the chemical contribution term is expressed by

$$
\begin{aligned}
g_{\mathrm{chem}}^{E} / R T & =x_{1} \ln \left(\varphi_{A_{1}} / \varphi_{A_{1}}^{\circ} x_{1}\right)+x_{2} \ln \left(\varphi_{2} / x_{2}\right)+x_{3} \ln \left(\varphi_{3} / x_{3}\right)+x_{2}+x_{3} \\
& +x_{1} r_{1} / S^{\circ}-\left(x_{1} r_{1}+x_{2} r_{2}+x_{3} r_{3}\right) / S+(Z / 2) \sum_{i}^{3} q_{i} x_{i} \ln \left(\theta_{i} / \varphi_{i}\right)
\end{aligned}
$$

The last term on the right hand side of Eq. (16) includes shape effect and this term does not appear in the previous equations [1-3], provided that the segment fractions correspond to the volume fractions in the latter equations.

For continuous linear associating reactions of alcohol molecules, two models have been proposed. They differ from each other in defining the chemical equilibrium constant: the Kretschmer-Wiebe and the Mecke-Kempter models. The Kretschmer-Wiebe Model. KRETscHMER and WIEBE [1] suggested the following chemical equilibrium constant given by

$$
K^{\varphi}=\left(\varphi_{A_{i}} / \varphi_{A_{1}} \varphi_{A_{i-1}}\right)(i-1) / i .
$$

Then, we may obtain the segment fractions of alcohol monomer in the solution and in pure alcohol.

$$
\begin{aligned}
& \varphi_{A_{1}}=\left[2 K^{\varphi} \varphi_{1}+1-\left(1+4 K^{\varphi} \varphi_{1}\right)^{1 / 2}\right] / 2\left(K^{\varphi}\right)^{2} \varphi_{1} \\
& \varphi_{A_{1}}^{\circ}=\left[2 K^{\varphi}+1-\left(1+4 K^{\varphi}\right)^{1 / 2}\right] / 2\left(K^{\varphi}\right)^{2} .
\end{aligned}
$$


$1 / S$ and $1 / S^{\circ}$ are, respectively, expressed by

$$
\begin{aligned}
1 / S & =\varphi_{A_{1}} / r_{1}\left(1-K^{\varphi} \varphi_{A_{1}}\right)+\varphi_{2} / r_{2}+\varphi_{3} / r_{3} \\
1 / S^{\circ} & =\varphi_{A_{1}}^{\circ} / r_{1}\left(1-K^{\varphi} \varphi_{A_{1}}^{\circ}\right) .
\end{aligned}
$$

We may define $K^{\theta}$ in terms of the surface fraction in the same way as $K^{\varphi}$.

$$
K^{\theta}=\left(\theta_{A_{i}} / \theta_{A_{1}} \theta_{A_{i-1}}\right)(i-1) / i .
$$

Dividing Eq. (22) by Eq. (17) gives

$$
K^{\theta} / K^{\varphi}=\left[\theta_{A_{i}} /\left(\theta_{A_{1}} \theta_{A_{i-1}}\right)\right]\left[\varphi_{A_{i}} /\left(\varphi_{A_{1}} / \varphi_{A_{i-1}}\right)\right]^{-1}=\varphi_{A_{1}} / \theta_{A_{1}}=\varphi_{1} / \theta_{1}
$$

Eq. (23) suggests $\lim _{x_{1} \rightarrow 1} \varphi_{A_{1}} / \theta_{A_{1}}=\varphi_{A_{1}}^{\circ} / \theta_{A_{1}}^{\circ}=1$.

The Mecke-Kempter Model. Kentatan and Treszczanowicz [11] presented detailed discussions on the Mecke-Kempter model. The results are summarized below.

$$
\begin{aligned}
K^{\varphi} & =\varphi_{A_{1}} /\left(\varphi_{A_{1}} \varphi_{A_{i-1}}\right) \\
\varphi_{A_{1}} & =\varphi_{1} /\left(1+K^{\varphi} \varphi_{1}\right) \\
\varphi_{A_{1}}^{\circ} & =1 /\left(1+K^{\varphi}\right) \\
1 / S & =-\ln \left(1-K^{\varphi} \varphi_{A_{1}}\right) / r_{1} K^{\varphi}+\varphi_{2} / r_{2}+\varphi_{3} / r_{3} \\
1 / S^{\circ} & =-\ln \left(1-K^{\varphi} \varphi_{A_{1}}^{\circ}\right) / r_{1} K^{\varphi} .
\end{aligned}
$$

The physical (= residual) contribution term of the solution is expressed by Eq. (29) (see Appendix 2).

$$
g^{E}(\text { physical }) / R T=-\left(\sum_{i}^{3} q_{i} x_{i} \ln \sum_{j}^{3} \theta_{j} \tau_{j i}\right)
$$

which gives, when differentiated,

$$
\ln \left(\gamma_{i}\right)_{\mathrm{phys}}=-q_{i} \ln \left(\sum_{j}^{3} \theta_{j} \tau_{j i}\right)+q_{i}-q_{i} \sum_{j}^{3} \frac{\theta_{j} \tau_{i j}}{\sum_{j}^{3} \theta_{k} \tau_{k j}}
$$

The activity coefficient of component $i$ is obtained by

$$
\ln \gamma_{i}=\ln \left(\gamma_{i}\right)_{\mathrm{chem}}+\ln \left(\gamma_{i}\right)_{\mathrm{phys}} .
$$




\section{Excess Enthalpy}

The excess enthalpy is given as the sum of two contribution terms: the one is chemical and the other physical.

$$
h^{E}=h_{\text {chem }}^{E}+h_{\text {phys }}^{E} .
$$

Expressions of the chemical contribution term for two models are available elsewhere $[12,13]$.

For the Kretschmer-Wiebe model, KreitataN and TreszczanowICZ [12] derived

$$
h_{\mathrm{chem}}^{E}=h^{\circ} x_{1} K^{\varphi}\left(\varphi_{A_{1}}-\varphi_{A_{1}}^{\circ}\right)
$$

where $h^{\circ}$ is the enthalpy of hydrogen bond formation.

For the Mecke-Kempter model, Treszczanowicz [13] presented

$$
h_{\text {chem }}^{E}=h^{\circ} x_{1}\left[\ln \left(1+K^{\varphi}\right) / K^{\varphi}-\ln \left(1+K^{\varphi} \varphi_{1}\right) / K^{\omega} \varphi_{1}\right] .
$$

The physical term is given by applying the Gibbs-Helmholtz relation to Eq. (29).

$$
h_{\mathrm{phys}}^{E}=\frac{\partial\left(g_{\mathrm{phys}}^{R} / T\right)}{\partial(1 / T)}=-R \sum_{i}^{3} q_{i} x_{i} \frac{\sum_{j}^{3} \theta_{j} \frac{\partial \tau_{j t}}{\partial(1 / T)}}{\sum_{j}^{3} \theta_{j} \tau_{j i}} .
$$

\section{Data reduction}

Abrams and Pradsnitz [6] suggested that the structural parameters $r$ and $q$ are, respectively, the van der Waals volume and area of the molecule relative to a standard segment.

$$
\begin{aligned}
& r_{i}=v_{i} / v^{*} \\
& q_{i}=a_{i} / a^{*}
\end{aligned}
$$

where $v^{*}$ and $a^{*}$ are the normalization factors which are connected with the van der Waals volume and area of the standard segment.

VERA et al. [9] obtained a linear relation between $a_{i}$ and $v_{i}$ as calculated by BoNDI [14] over many branched or unbranched chain molecules including alkanes, alcohols, aldehydes, ketones, nitriles, and esters.

$$
\begin{aligned}
& a_{i}=k_{1} v_{i}+k_{2} \\
& k_{1}=\frac{Z-2}{Z} \frac{a^{*}}{v^{*}}=1.323 \times 10^{8} \mathrm{~cm}^{-1} \\
& k_{2}=2 a^{*} / Z=6.259 \times 10^{8} \mathrm{~cm}^{2} / \mathrm{mol} .
\end{aligned}
$$


For the assumed value of $Z=10, a^{*}$ is obtained from Eq. (40) and then $v^{*}$ from Eq. (39).

Combining Eqs. (38-40) gives

$$
Z q_{i}=0.4228 v_{i}+2
$$

To include molecules with more complex geometry, VERA et al. [9] presented a generalizing equation for molecules of any size and shape by introducing the bulk factor $l_{i}$.

$$
Z q_{i}=0.4228 v_{i}+2\left(1-l_{i}\right)
$$

For open chain molecules, branched or unbranched, $l_{i}=0$ according to GUGGENHEIM [7]. For cyclic molecules, VERA et al. [9] suggested $l_{i}=1$. These rules are not retained by the structural parameters which are obtained in accordance with the method of ABrams and Prausnitz [6]. We follow the method of VERA et al. [9]. Table 1 lists the values of $r$ and $q$ for pure components. We used only the single value of $h^{\circ}=-6 \mathrm{kcal} / \mathrm{mol}$ for all alcohols as proposed by RENon and Pratusnitz [2]. This value fixes the temperature dependence of the chemical equilibrium constant according to the van't Hoff equation.

$$
\frac{\partial \ln K^{\varphi}}{\partial(1 / T)}=-\frac{h^{\circ}}{R}
$$

Table 2 shows the chemical equilibrium constants for alcohols at $50^{\circ} \mathrm{C}$.

\begin{tabular}{|c|c|c|c|c|c|c|c|}
\hline Component & $r$ & $q$ & $l$ & Component & $r$ & $q$ & $l$ \\
\hline Methanol & 1.15 & 1.12 & 0 & $n$-Hexane & 3.61 & 3.09 & 0 \\
\hline Ethanol & 1.69 & 1.55 & 0 & n-Heptane & 4.15 & 3.52 & 0 \\
\hline 1-Propanol & 2.23 & 1.98 & 0 & $\begin{array}{l}\text { 2,2,4-Trimethyl- } \\
\text { pentane }\end{array}$ & 4.51 & 3.81 & 0 \\
\hline 2-Propanol & 2.23 & 1.98 & 0 & $n$-Tetradecane & 7.93 & 6.55 & 0 \\
\hline 1-Butanol & 2.77 & 2.42 & 0 & Cyclopentane & 2.64 & 2.11 & 1 \\
\hline Cyclopentanol & 2.88 & 2.30 & 1 & Cyclohexane & 3.18 & 2.55 & 1 \\
\hline Cyclohexanol & 3.43 & 2.74 & 1 & Methylcyclohexane & 3.72 & 2.98 & 1 \\
\hline
\end{tabular}
Those values were obtained by considering all data for binary alcohol

Table 1. Values of the pure component structure parameters 
Table 2. Values of the chemical equilibrium constants at $50^{\circ} \mathrm{C}$

\begin{tabular}{llc}
\hline Alcohol & \multicolumn{2}{c}{ Chemical equilibrium constants } \\
\cline { 2 - 3 } & Kretschmer-Wiebe & Mecke-Kempter \\
\hline & & \\
Methanol & 280 & 350 \\
Ethanol & 170 & 170 \\
1-Propanol & 90 & 110 \\
2-Propanol & 60 & 85 \\
1-Butanol & 80 & 95 \\
Cyclopentanol & 80 & 80 \\
Cyclohexanol & 70 & 70 \\
\hline
\end{tabular}

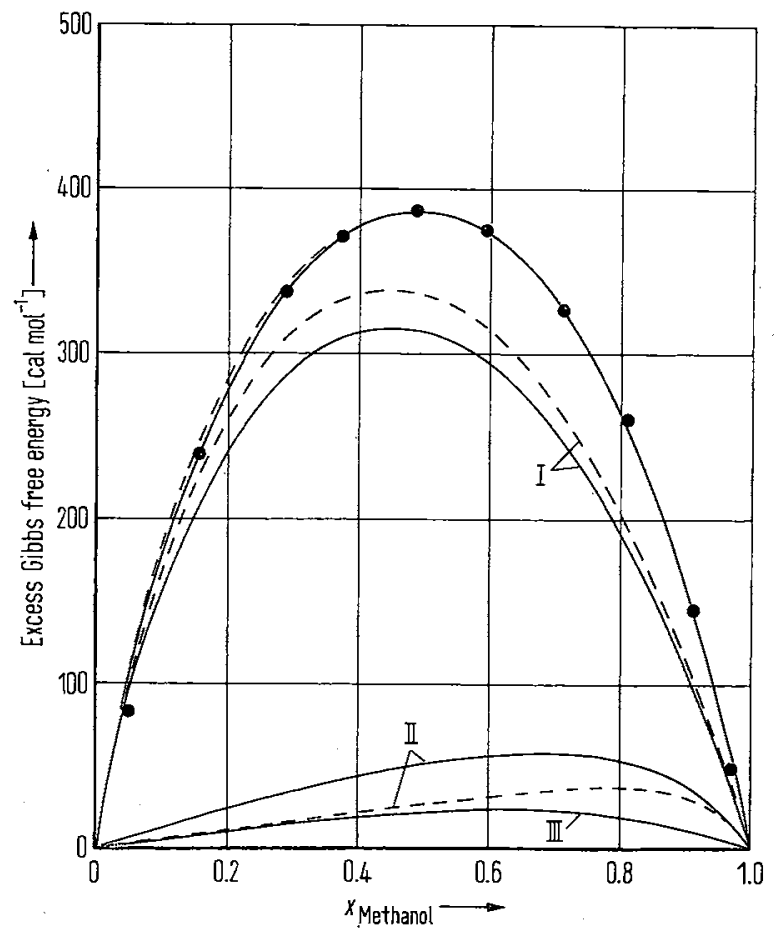

Fig. 1. $g^{E}$ vs. liquid mole fraction diagram for the methanol-cyclohexane system at $55^{\circ} \mathrm{C}$ : experimental data of Marinrchev and Susarev [15]; - calculated by the Kretschmer-Wiebe model; - - calculated by the Mecke-Kempter model:

I. $\sum_{i}^{2} x_{i} \ln \left(\varphi_{i} / x_{i}\right) ; \quad$ II. $(Z / 2) \sum_{i}^{2} q_{i} x_{i} \ln \left(\theta_{i} / \varphi_{i}\right) ; \quad$ III. $-\sum_{i}^{2} q_{i} x_{i} \ln \left(\sum_{j}^{2} \theta_{j} \tau_{j i}\right)$. 
Table 3. Calculated results for binary

\begin{tabular}{llll}
\hline System (1-2) & Temp. & No. of & $g^{E}$ \\
& ${ }^{\circ} \mathrm{C}$ & data & or \\
& & points & $h^{E}$
\end{tabular}

$\begin{array}{lrrr}\text { Methanol- } n \text {-hexane [17] } & 45 & 9 & g^{E} \\ \text { Methanol- } n \text {-hexane [18] } & 45 & 17 & h^{E} \\ \text { Methanol-cyclohexane [15] } & 55 & 10 & g^{E} \\ \text { Ethanol- } n \text {-hexane [19] } & 55 & 9 & g^{E} \\ \text { Ethanol-cyclohexane [20] } & 20 & 7 & g^{E} \\ \text { Ethanol-cyclohexane [21] } & 20 & 5 & h^{E} \\ \text { Ethanol-cyclohexane [22] } & 25 & 21 & h^{E} \\ \text { Ethanol-methylcyclohexane [23] } & 35 & 8 & g^{E} \\ \text { Ethanol-methylcyclohexane [24] } & 25 & 11 & h^{E} \\ \text { Ethanol- } n \text {-heptane [25] } & 20 & 4 & g^{E} \\ \text { Ethanol- } n \text {-heptane [26] } & 10 & 21 & h^{E} \\ \text { Ethanol- } n \text {-heptane [21] } & 20 & 5 & h^{E} \\ \text { Ethanol-2,2,4-trimethylpentane [27] } & 50 & 13 & g^{E} \\ \text { Ethanol-2,2,4-trimethylpentane [28] } & 25 & 7 & h^{E} \\ \text { 1-Propanol- } n \text {-heptane [29] } & 60 & 19 & g^{E} \\ \text { 1-Propanol- } n \text {-heptane [30] } & 45 & 18 & h^{E} \\ \text { 1-Propanol- } n \text {-tetradecane [31] } & 30 & 15 & h^{E} \\ \text { 2-Propanol- } n \text {-heptane [29] } & 60 & 18 & g^{E} \\ \text { 2-Propanol- } n \text {-heptane [29] } & 30 & 26 & h^{E} \\ \text { 1-Butanol- } n \text {-hexane [32] } & 25 & 8 & h^{E} \\ \text { Cyclopentanol-cyclopentane [33] } & 25 & 14 & g^{E} \\ \text { Cyclopentanol-cyclohexane [34] } & 25 & 20 & g^{E} \\ \text { Cyclopentanol-cyclohexane [34] } & 25 & 25 & h^{E} \\ \text { Cyclohexanol-cyclopentane [34] } & 25 & 19 & g^{E} \\ \text { Cyclohexanol-cyclopentane [34] } & 25 & 17 & h^{E} \\ \text { Cyclohexanol-cyclohexane [33] } & 25 & 23 & g^{E} \\ \text { Cyclohexanol-cyclohexane [35] } & 25 & 33 & h^{E} \\ \text { Cyclohexane- } n \text {-heptane [21] } & 20 & 3 & g E \\ \text { Cyclohexane- } n \text {-heptane [21] } & 20 & 5 & h^{E} \\ & & & \end{array}$

a $\mathrm{I}=$ the Kretschmer-Wiebe model

solutions. Figure 1 illustrates the magnitude of each contribution term to the excess Gibbs free energy data of the methanol-cyclohexane system [15] at $55^{\circ} \mathrm{C}$. The $(Z / 2) \sum_{i}^{2} q_{i} x_{i} \ln \left(\theta_{i} / \varphi_{\imath}\right)$ term becomes appreciable in methanol solutions and it is negligible in other alcohol so- 
systems based on the Kretschmer-Wiebe model

Abs. arith. Values of parameters in the Krotschmer-Wiobe model mean devia-

tion

(cal $\mathrm{mol}^{-1}$ )

$I^{\text {\& }} \quad I I^{b}$

\begin{tabular}{ll}
$C_{1}$ & $C_{2}$ \\
\hline$(\mathrm{cal} \mathrm{mol}-1)$ &
\end{tabular}

$\begin{array}{ll}D_{1} & D_{2}\end{array}$

4.2

7.4

$-215.35$

478.62

$\begin{array}{lll}6.3 & 0.7 & -84.49\end{array}$

496.25

$-257.71$

539.63

$\begin{array}{lll}6.4 & 6.7 & 393.49\end{array}$

3.9

$5.0-51.71$

0.8

0.7

152.57

$-246.00$

168.59

1.0

$0.5 \quad-307.39$

920.17

555.98

- 33.81

153.85

2.9

2.7

114.58

458.40

$-17.7 .40$

345.67

$-123.67$

356.88

(cal mol-1 $\mathrm{K}^{-1}$ )

1.3

2.9

42.51

$-35.05$

406.96

110.80

88.16

495.95

208.64

$-115.72$

1350.03

31.31

159.92

193.24

$-117.18$

$-93.22$

179.02

239.38

593.21

$-236.98$

447.60

$-261.45$

445.84

93.37

403.34

$-205.31$

43.48

375.35

$-216.44$

70.74

485.83

40.72

$-22.15$

153.34

$\begin{array}{rr}0.5080 & 2.2557 \\ -1.3199 & 1.7184 \\ & \\ 0.9416 & 0.7517\end{array}$

0.2876

0.1247

- 94.80

0.3864

0.2693

0.6188

0.5242

0.2603

1.6149

6.1106

4.2752

1.9268

$-1.0742$

$-0.0941$

0.2509

0.5385

2.2236

0.3

-Kempter model

b II = the Mecke-Kempter model

lutions. In fitting the excess enthalpy data, we assumed that the energy parameters change with temperature linearly.

$$
u_{f i}-u_{i i}=C_{i}+D_{i}(T-273.15) \text {. }
$$

The simplex method developed by NeLDer and Mrad [16] was used to obtain the constants $C_{i}$ and $D_{i}$. Tables 3 and 4 present, re- 


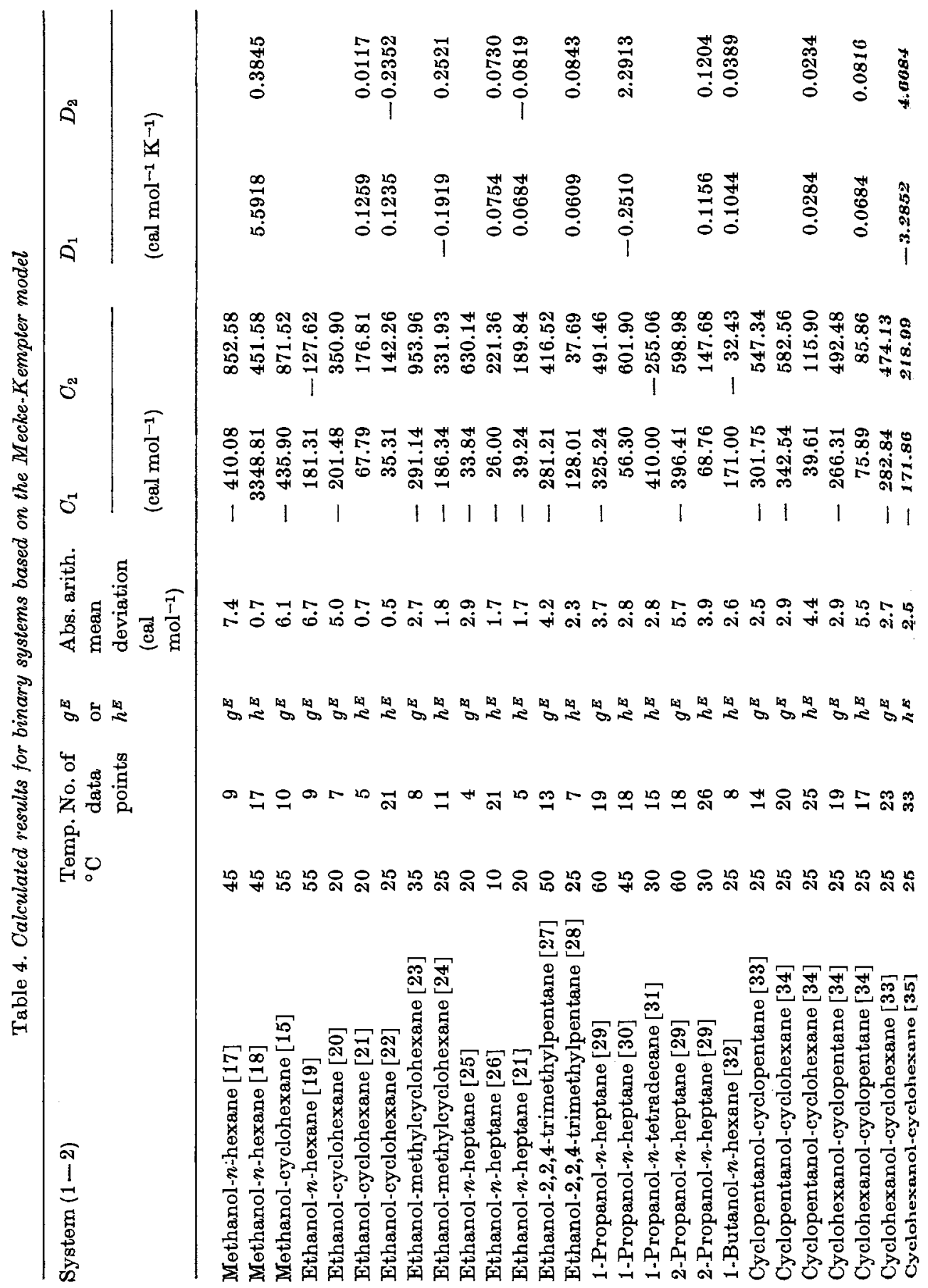




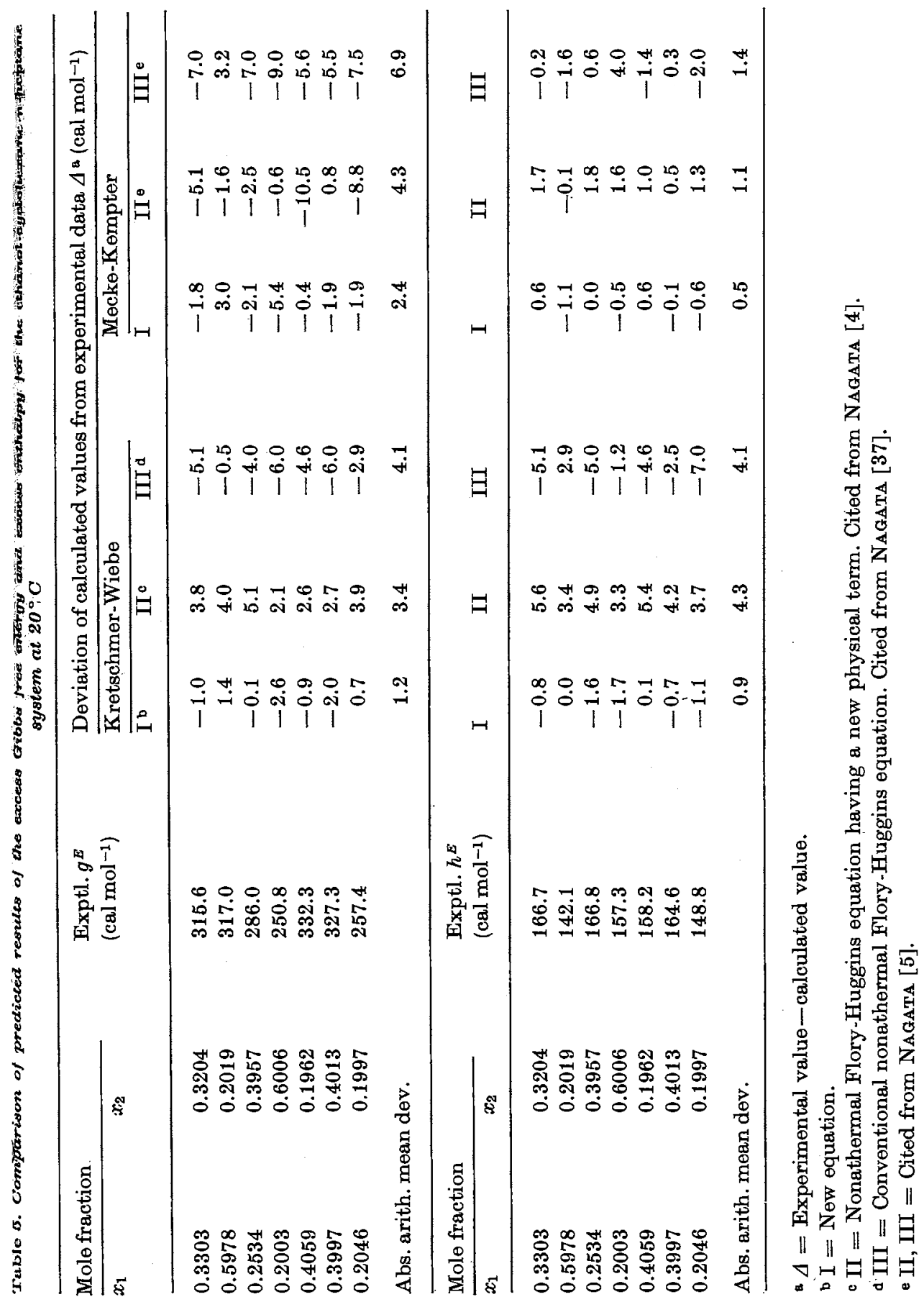




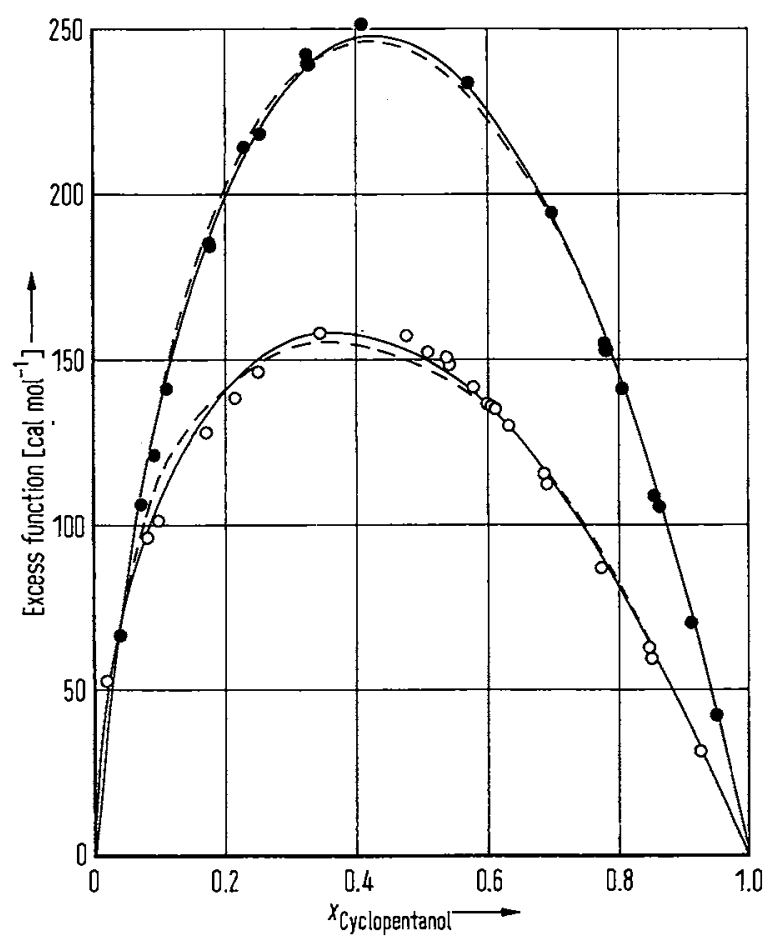

Fig. 2. Excess functions for the cyclopentanol-cyclohexane system at $25^{\circ} \mathrm{C}$ : - experimental $g^{E}$ data of Benson et al. [34]; O experimental $h^{E}$ data of Benson et al. [34]; —_ calculated by the Kretschmer-Wiebe model; - - calculated by the Mecke-Kempter model

spectively, calculated results for binary systems based on the Kretschmer-Wiebe and the Mecke-Kempter models. The goodness of fit is about the same for the two models. BECKER et al. [36] presented the results of least-squares fit of their models with chain association of one component to the excess Gibbs free energy data on cycloalkanolcycloalkane systems [33, 34] and found a good approximation of the concentration dependence of self-association. We applied the present theory to represent the excess properties for cycloalkanol-cycloalkane systems [33-35]. Tentatively we assumed $h^{\circ}=-6 \mathrm{kcal} / \mathrm{mol}$ as the enthalpy of hydrogen bond formation of cycloalkanols. Figures 2 and 3 show that the calculated results are in good agreement with the experimental data of these two systems. 


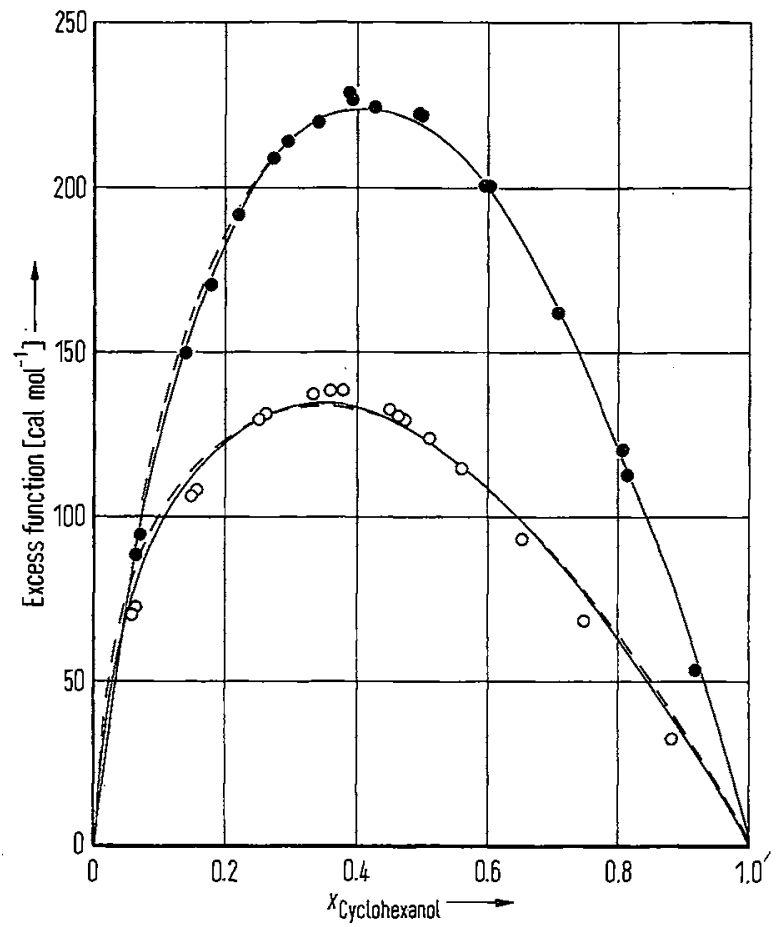

Fig. 3. Excess functions for the cyclohexanol-cyclopentane system at $25^{\circ} \mathrm{C}$ : - experimental $g^{E}$ data of Benson et al. [34]; O experimental $h^{E}$ data of Benson et al. [34]; - calculated by the Kretschmer-Wiebe model; - calculated by the Mecke-Kempter model

Table 5 lists a comparison of calculated and experimental values for the excess thermodynamic functions of the ethanol-cyclohexane- $n$ heptane system [21] at $20^{\circ} \mathrm{C}$. The calculated results were obtained from the binary parameters given in Tables 3 and 4 . The present theory seems to have a better predictive ability than the previous equations $[4,5,37]$ for the two association models.

Our forthcoming paper will be concerned with the extension of the present theory to alcohol-nonassociating active component systems.

\section{Acknowledgement}

We thank the Computation Center, Osaka University, and the Data Processing Centers, Kanazawa and Kyoto Universities, for the use of their facilities. 


\section{Appendix 1}

$$
\begin{aligned}
\sum_{j}^{\infty} \varphi_{A_{j}}\left(l_{1}-r_{1} l_{A_{j}} / r_{A_{j}}\right)+\varphi_{2}\left(l_{1}-r_{1} l_{2} / r_{2}\right)+\varphi_{3}\left(l_{1}-r_{1} l_{3} / r_{3}\right) \\
-\sum_{j}^{\infty} \varphi_{A_{j}}^{\circ}\left(l_{1}-r_{1} l_{A_{j}} / r_{A_{j}}\right) \\
=-r_{1}\left[\sum_{j}^{\infty} \varphi_{A_{j}}\left(l_{A_{1}}-1+1\right) / r_{A_{j}}+\varphi_{2}\left(l_{2}-1+1\right) / r_{2}+\varphi_{3}\left(l_{3}-1+1\right) / r_{3}\right] \\
+r_{1} \sum_{j}^{\infty} \varphi_{A_{j}}^{\circ}\left(l_{A_{j}}-1+1\right) / r_{A_{j}}+l_{1}\left(\sum_{j}^{\infty} \varphi_{A_{j}}+\varphi_{2}+\varphi_{3}-\sum_{j}^{\infty} \varphi_{A_{j}}^{\circ}\right) \\
=r_{1}\left[\sum_{j}^{\infty} \varphi_{A_{j}}\left(1-l_{A_{j}}\right) / r_{A_{j}}+\varphi_{2}\left(1-l_{2}\right) / r_{2}+\varphi_{3}\left(1-l_{3}\right) / r_{3}\right] \\
-r_{1}\left(\sum_{j}^{\infty} \varphi_{A_{j}} / r_{A_{1}}+\varphi_{2} / r_{2}+\varphi_{3} / r_{3}\right) \\
\quad-r_{1} \sum_{j}^{\infty} \varphi_{A_{j}}\left(1-l_{A_{j}}\right) / r_{A_{j}}+r_{1} \sum_{j}^{\infty} \varphi_{A_{j}}^{\circ} / r_{A_{j}} \\
\quad=r_{1}\left[\varphi_{1}\left(1-l_{1}\right) / r_{1}+\varphi_{2}\left(1-l_{2}\right) / r_{2}+\varphi_{3}\left(1-l_{3}\right) / r_{3}\right] \\
-r_{1} / S+r_{1} / S^{\circ}+l_{1}-1
\end{aligned}
$$

where

$$
\begin{aligned}
1 / S & =\sum_{j}^{\infty} \varphi_{A_{j}} / r_{A_{3}}+\varphi_{2} / r_{2}+\varphi_{3} / r_{3} \\
1 / S^{\circ} & =\sum_{j}^{\infty} \varphi_{A_{j}}^{\circ} / r_{A_{j}} .
\end{aligned}
$$

\section{Appendix 2}

The physical contribution term of a multicomponent system of the chemical species $A_{1}, A_{2}, \ldots A_{n}$ and inert components (2 and 3 ) is expressed by Eq. (3).

$$
\begin{aligned}
g^{E}(\text { physical }) / R T= & -\sum_{i}^{\infty} q_{A_{i}} x_{A_{i}} \ln \left(\theta_{2} \tau_{2 A_{i}}+\theta_{3} \tau_{3 A_{i}}+\sum_{j}^{\infty} \theta_{A_{j}} \tau_{A_{i} A_{3}}\right) \\
& -g_{2} x_{2} \ln \left(\theta_{2}+\theta_{3} \tau_{32}+\sum_{i}^{\infty} \theta_{A_{i}} \tau_{A_{i} 2}\right) \\
& -q_{3} x_{3} \ln \left(\theta_{2} \tau_{23}+\theta_{3}+\sum_{i}^{\infty} \theta_{A_{i}} \tau_{A_{i} 3}\right)
\end{aligned}
$$


We assume that $\tau_{A_{i} A_{j}}, \tau_{A_{i} 2}$, and $\tau_{A_{i} 3}$ are independent of the subscripts $i$ and $j$. Recalling that

$$
\sum_{i}^{\infty} \theta_{A_{i}}=\theta_{1} \text {, and } \sum_{i}^{\infty} q_{A_{i}} x_{A_{i}}=q_{1} \sum_{i}^{\infty} i x_{A_{i}}=q_{1} x_{1}
$$

we obtain

$$
\begin{aligned}
g^{E}(\text { physical }) / R T= & -q_{1} x_{1} \ln \left(\theta_{1}+\theta_{2} \tau_{21}+\theta_{3} \tau_{31}\right) \\
& -q_{2} x_{2} \ln \left(\theta_{1} \tau_{12}+\theta_{2}+\theta_{3} \tau_{32}\right) \\
& -q_{3} x_{3} \ln \left(\theta_{1} \tau_{13}+\theta_{2} \tau_{23}+\theta_{3}\right) \\
= & -\sum_{i}^{3} q_{i} x_{i} \ln \left(\sum_{j}^{3} \theta_{j} \tau_{j l}\right)
\end{aligned}
$$

where

$$
\tau_{j t}=\exp \left[-\left(u_{f t}-u_{t i}\right) / R T\right]
$$

\section{References}

1. C. B. Kretschuer and R. Wiebe, J. Chem. Physics 22 (1954) 425.

2. H. Renon and J. M. Pratsnttz, Chem. Engng. Sci. 22 (1967) 299, Errata, 1891.

3. I. A. WIEHE and E. B. Bagley, Ind. Engng. Chem. Fundamentals 6 (1967) 209.

4. I. Nagata, Fluid Phase Equilibria 1 (1977) 93.

5. I. Nagata, Z. physik. Chem. Neue Folge 107 (1977) 39.

6. D. S. Abrams and J. M. Prausnitz, AIChE J. 21 (1975) 116.

7. E. A. GugGenheim, Mixtures. Clarendon Press, Oxford 1952.

8. G. M. Wilson, J. Amer. chem. Soc. 86 (1964) 127.

9. J. H. Vera, S. G. SAYEgh and G. A. RAtChIfF, Fluid Phase Equilibria 1 (1977) 113.

10. L. Prigogine and R. Defay, Chemical Thermodynamics. Wiley, New York 1954.

11. H. Kehtatan and A. Treszczanowicz, Bull. Acad. polon. Sci., Ser. Sci. Chim. 14 (1966) 891.

12. H. Kemiatan and A. Treszczanowicz, Bull. Soc. Chim. France 18 (1969) 1561.

13. A. Treiszczanowrcz, Bull. Acad. polon. Sci., Ser. Sci. Chim. 21 (1973) 189.

14. A. Bondr, Physical Properties of Molecular Crystals, Liquids and Glasses. Wiley, New York 1968.

15. A. N. Mariniohev and M. P. Susarev, Zh. Prikladnoi Khimii 38 (1965) 1619.

16. J. A. NELDER and R. MEAD, Computer J. 7 (1965) 308.

17. J. B. Feruguson, J. physic. Chem. 36 (1932) 1123.

18. C. G. Savini, D. R. Winterhalter and H. C. Vax Ness, J. chem. Engng. Data 10 (1965) 171. 
19. L. S. Kudryavisteva and M. P. Susarev, Zh. Prikladnoi Khimii 36 (1963) 1471.

20. G. Scatchard and F. G. Satrotewicz, J. Amer. chem. Soc. 86 (1964) 130.

21. H. Grosse-Wortmann, W. Jost and H. Gg. Wagner, Z. physik. Chem. Neue Folge 49 (1966) 74.

22. I. Nagata and K. KazUMa, J. chem. Engng. Data 22 (1977) 79.

23. C. B. Kretschmer and R. Wiebe, J. Amer. chem. Soc. 71 (1949) 3176.

24. I. Nagata and T. Yamada, Ind. Engng. chem. Process Des. Develop. 13 (1974) 47.

25. I. KLesper, Z. physik. Chem. Neue Folge 51 (1966) 1.

26. H. C. Van Ness, C. A. Soczer and N. K. Kochar, J. chem. Engng. Data 12 (1967) 346.

27. C. B. Kretschmer, J. Nowakowska and R. Wrebe, J. Amer. chem. Soc. 70 (1948) 1785.

28. I. Brown and W. Fock, Austral. J. Chem. 8 (1955) 361.

29. H. C. Van Ness, C. A. Soczek, G. L. Peloquin and R. L. Machado, J. chem. Engng. Data 12 (1967) 217.

30. C. G. Savin, D. R. Winterhatter and H. C. Van Ness, J. chem. Engng. Data 10 (1965) 168.

31. R. S. RamalHo and M. RUEL, Canad. J. chem. Engng. 46 (1968) 456.

32. I. Brown, W. Foor and F. Sintr, Austral. J. Chem. 17 (1964) 1106.

33. G. C. Benson, S. Murakami and D. E. G. Jones, J. chem. Thermodyn. \$ (1971) 719 .

34. G. C. Benson, S. C. Anand and O. Kiyohara, J. chem. Engng. Data 19 (1974) 258.

35. D. E. G. Jones, I. A. Weeks, S. C. Anand, R. W. Wetmore and G. C. Benson, J. chem. Engng. Data 17 (1972) 501.

36. F. BECKER, M. KTEFER, P. RHENSIUS and H. D. SCHÄHER, Z. Naturforsch. 31 (1976) 1651.

37. I. Nagata, Z. physik. Chem. Neue Folge 85 (1973) 241. 